\title{
Study on the Human Resources of Soft Power Establishment in Chongqing's Construction of National Central City
}

\author{
Bin Wang ${ }^{1} \&$ Lu Zhou ${ }^{2}$ \\ ${ }^{1}$ School of Politics and Public Management, Southwest University, Chongqing, P.R. China \\ 2 Balance urban and rural public cultural service collaborative innovation center, Southwest University, \\ Chongqing, P.R. China \\ Correspondence: Bin Wang, School of Political Science and Public Management, Southwest University, \\ Chongqing, China. Tel: 1-399-600-2482.E-mail: swu_pm@163.com
}

Received: September 17, 2013 Accepted: November 11, 2013 Online Published: April 29, 2014

doi:10.5539/par.v3n1p80 URL: http://dx.doi.org/10.5539/par.v3n1p80

Financed by State Ethnic Affairs Commission research project, Authorized Number: 2013-GM-074

\begin{abstract}
Human resources, as the important part of soft power establishment, have immeasurable influence on Chongqing's national central city construction. Therefore, the importance of the human resources of soft power establishment to Chongqing's construction of national central city was first analyzed. Then, SWOT matrix method was adopted in this paper to analyze the present condition, advantages, disadvantages, opportunities and challenges of Chongqing's human resources' soft power. In the end, the relevant suggestions and advices of Chongqing's the human resources of soft power establishment were proposed during the process of national central city construction.
\end{abstract}

Keywords: national central city, human resources, soft power, establishment

\section{Introduction}

The concept of national central city was first mentioned in 2005 by Construction Department when establishing national city and town systematic plan according to City's Plan Law, namely "the city with the function to lead, radiate and distribute others" - top city of national city and town system. In February 2010, Chongqing was authorized as national central city (NCC in the following) in National City and Town Systematic Plan by Town and Country Construction Department - the only one in the west area. Central city was the center of politics and administration management, transportation, information, science and technology, and distributing place of human resources. Multiple measures as Economic - such as financial and monetary, political, taxation revenue, and human resources training should be adopted to promote economic development. Therefore, the central city cannot develop without human resources, and at the same time, human resources (HUMAN RESOURCES in the following), as the pillar of every field, are one of the key factors of central city development and the development of HUMAN RESOURCES soft power should be strengthened gradually.

\section{The Human Resources of Soft Power Establishment Is the Key Factor to NCC Construction}

The comprehensive power of a city is composed by soft power and hard power, having impact on the survival and development of city's inner strength and outer influence. Human resources, as the important part of soft power establishment, have immeasurable effect to NCC construction.

\subsection{Position and Localization of Human Resources of Soft Power in City's Soft Power}

\subsubsection{Position of Human Resources of Soft Power in City Soft Power}

Soft power is used in international relations theory to describe the ability of a political body to indirectly influence the behavior or interests of other political bodies through cultural or ideological means. The phrase was coined by Joseph Nye of Harvard University in a 1990 book, Bound to Lead: The Changing Nature of American Power. He further developed the concept in his 2004 book, Soft Power: The Means to Success in World Politics. Joseph Nye coined the term "soft power" to describe a nation's ability to attract and persuade, soft power arises from the attractiveness of its culture, political ideals, and policies. While a city's soft power is a complicated 
system which has multiple sub-systems to influence each other, such as culture, government management, opening degree, human's quality, city image. And as the embodiment and insurance of city's soft power, human's quality is the source of gradual development of soft power and plays a key role in promoting city's competitive power.

\subsubsection{Localization of Human Resources of Soft Power in City's Soft Power}

In accordance with the Chinese government on human resource definition of soft power, human resources of soft power in this paper refer to human resources with master or doctor degree or high professional titles, including every department and organization like enterprises, institutions, government authorities. As the elite of human resource in city's soft power, human resources are the people with extraordinary contribution and special skills in any field, and the crucial intelligence resource which can create, develop, integrate and optimize other resources and cannot be replaced. Influencing the core competitive power of nation and area, the amount and structure of human resources will be conditioned by city's development and play irreplaceable role in promoting soft power. Human resources of soft power are the root to construct Chongqing into human resources center of western China, inland opening-up city, economic center in the upper and middle reaches of Yangtze River, key growing part in western area, accelerate the development and finally embody the position as NCC.

\section{Condition of Chongqing Human Resources of Soft Power}

Since Chongqing was authorized as city directly under the administration of central government, the strategic idea to construct powerful Chongqing with human resources and develop through science and education has rooted. With the gradual stimulation of human resources construction, human resources teams are formed and steadily become inner power to drive Chongqing's development.

\subsection{Quantity of Chongqing Human Resources of Soft Power}

The quantity of Chongqing human resources of soft power has increased rapidly. There are nine academicians of Chinese Academy of Sciences and Engineering, 43 young and middle aged experts with extraordinary contribution to the nation, 53 national human resources in "Millions of Talents Engineer in New Century" and 43 postdoctoral mobile stations till 2012. However, compared with other national central cities, Chongqing doesn't have any advantage in the quantity of human resources of soft power.

\subsection{Quality of Chongqing Human Resources of Soft Power}

The quality of human resources of soft power can be observed from educational qualification and professional titles. As for the educational, human resources with professional skills in Chongqing has reached 441,963 till 2012, among which human resources (with master and doctor degree) reached 12,839, taking up 2.8\%; while general human resources (undergraduate and junior college degree) $79.4 \%$. For the professional, senior reached $8.9 \%$.

\subsection{Structure of Chongqing Human Resources of Soft Power}

The structure of Chongqing human resources of soft power can be analyzed from the following aspects: firstly, the age structure of human resources who are the crucial power to promote Chongqing's science and technology, culture and economic development is featured with young, except that the academicians of Chinese Academy of Sciences and Engineering are comparatively older. Secondly, from the aspect of majors' structure, human resources in the natural science are far beyond that in humanity and social science. Taking national talents in Millions of Talents Engineer and Extraordinary Youth Fund winners for example, most of the people are in natural science, taking up $86.18 \%$, while humanity and social science only taking up $13.82 \%$. Thirdly, from the aspect of vocation, taking the academicians of Chinese Academy of Engineering for example, with the development of education cause, especially the improvement of science and research environment and condition, and the emphasis of government, colleges and universities, most of the academicians of Chinese Academy of Engineering of Chongqing are in colleges and universities which are important places to cultivate human resources, taking up $88.89 \%$.

\subsection{Influence of Chongqing Human Resources of Soft Power Development on Central City Construction}

\subsubsection{Contribution of Human Resources of Soft Power to Chongqing's Economic and Social Development}

Till now, human resources have made great contribution to Chongqing's economic and social development, which can be mainly analyzed from four aspects: first, the number of awards is growing comparatively rapid, for instance, the number of Science and Technology Progress Award, Natural Science Award and Technical Invention Award has increased from 104 to 151 from 2006 to 2012; second, the number of patents application has increased greatly, but there is still a gap between Chongqing and other big cities; third, for the aspect of 
social and economic benefit, the economic development has been accelerated greatly through technology development, consultation and service; fourth, the number of academic papers of Chongqing University, Southwest University and other 14 universities has increased steadily from 2006 to 2012, especially the papers indexed by international index systems.

\subsubsection{The Development of Chongqing Human Resources of Soft Power Will Accelerate NCC Construction}

Human resources teams not only have close relation to Chongqing's economic development, but deeply influence the growing speed. Based on multiple factors correlation and according to human resources and economic data from Chongqing's "Twelve five-year-plan", government report and Statistics Bureau, the correlation between the number of Chongqing human resources and GDP growth is analyzed.

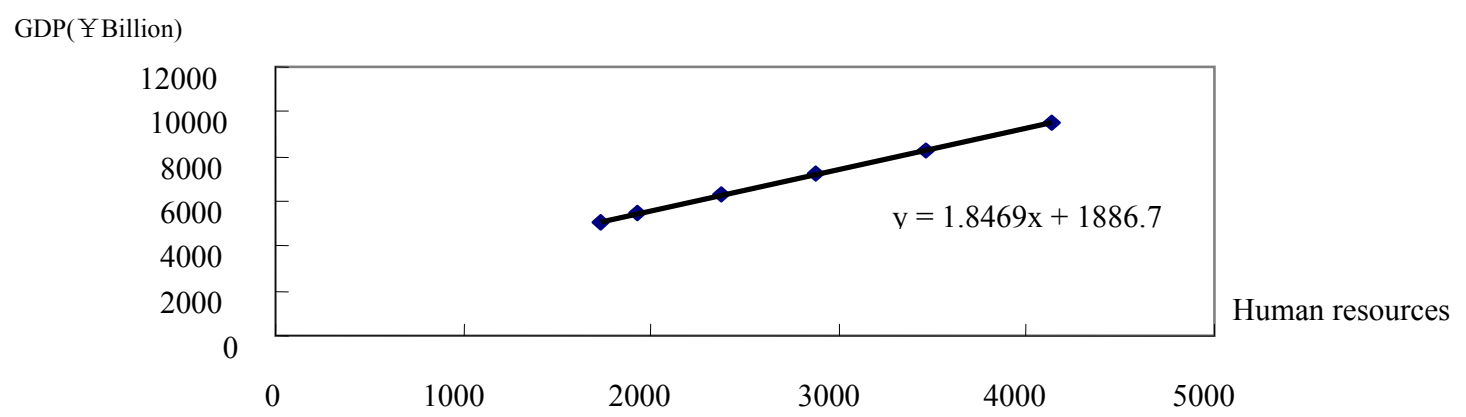

Figure 1 Correlation analysis between Chongqing's GDP growth and total amount of human resources

It can be easily seen from figure 1 that human resources growth has positive correlation to Chongqing's GDP. The more the total amount of human resources is the more rapid the economic grows. Therefore, the reinforcement of human resources of soft power will increase Chongqing's economic total amount, promote comprehensive competitive power and finally reach the target of constructing NCC.

\section{SWOT Analysis of Human Resources of Soft Power Development during NCC Construction}

To clear the basis and condition of human resources of soft power development in Chongqing NCC construction and smooth the development idea to make development strategy plan, SWOT (Strengths, Weaknesses, Opportunities and Threats) matrix is used to deeply analyze Chongqing human resources of soft power.

Table 1. SWOT matrix analysis of Chongqing human resources of soft power

\begin{tabular}{|c|c|c|c|}
\hline \multicolumn{4}{|c|}{ Inner condition } \\
\hline \multirow{14}{*}{ 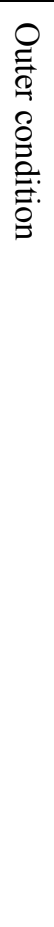 } & & S1: good strategy localization & W1: lower competitive power \\
\hline & & S2: special policy support & W2: singular human resources \\
\hline & & S3: good geological position & cultivation pattern \\
\hline & & S4: competitive power grows & W3: incomplete market allocation \\
\hline & & S5: solid infrastructure & $\begin{array}{l}\text { W4: faulty human resources quality } \\
\text { and structure }\end{array}$ \\
\hline & & & $\begin{array}{l}\text { W5: vague role in human resources } \\
\text { development }\end{array}$ \\
\hline & O1: industry transferring & & \\
\hline & $\begin{array}{l}\mathrm{O} 2: \text { human resources highland } \\
\text { construction }\end{array}$ & SO & WO \\
\hline & O3:transportation hub & & \\
\hline & O4: western China development & & \\
\hline & T1: human resources market abroad & & \\
\hline & $\begin{array}{l}\text { T2:developed area human resources } \\
\text { gathering }\end{array}$ & ST & WT \\
\hline & T3: sharp area competition & & \\
\hline & T4: insufficient environment & & \\
\hline
\end{tabular}




\subsection{SO Analysis of Chongqing Human Resources of Soft Power Development}

SO means that during the process of constructing NCC Chongqing should fully take the advantages inside and developing opportunities outside to strengthen human resources of soft power development. First, Chongqing is authorized to be more than 10 "golden positions", such as NCC, financial center and comprehensive transportation hub on the upper and middle reaches of Yangtze River, inland export commodity producing base and pioneer area for opening-up which provides favorable developing policies. Chongqing should fully take these advantages, positively grasp the opportunity of central and western "human resources highland" construction, attract more human resources to work in Chongqing and promote city's soft power. Second, having the aid of rapid economic development and steady growth of city's competitive power, Chongqing should grasp the industry transferring opportunity of domestic and abroad to cultivate and import human resources. Moreover, Chongqing is the crucial base of China's "three lines" construction. With further promoting Western Development, a huge city circle is formed around Chongqing, providing numbers of human resources for Chongqing's human resources of soft power promoting. So with solid infrastructure, Chongqing should grasp the opportunity of Western Development, strengthen human resources cultivation and platform construction to achieve human resources of soft power development.

\subsection{ST Analysis of Chongqing Human Resources of Soft Power Development}

ST means that during the process of NCC construction, Chongqing should fully take the inner advantage to confront and solve the threats and challenges, display the advantage to meet threats and promote Chongqing human resources of soft power. First, the favorable human resources developing policy and environment should be fully displayed. According to "314" plan's "five-Chongqing" construction policy, the insufficient in environment construction should be remedied to ensure human resources can be imported, stay and be employed to the right job. Then having the aids of rapid economic development, solid infrastructure, favorable living condition and transportation, Chongqing should actively confront the threats-- human resources competition from developed area and human resources market abroad and improve the attractive power of human resources. What's more, taking the aid of geological advantage, the construction of NCC should be accelerated and negative influences of human resources import competition and cost increasing should be decreased fully.

\subsection{WO Analysis of Chongqing Human Resources of Soft Power Development}

WO means that during the process of NCC construction, Chongqing should actively create conditions and grasp developing opportunity and further increase the overall human resources of soft power. First, Chongqing should fully take the advantage of industry transferring domestic and abroad to strengthen the construction of human resources development platform, attract more human resources working in Chongqing and fill up the disadvantages in human resources quantity, quality and structure. Then the opportunity of central and western human resources highland construction should be fully employed to compensate the disadvantages in less competitive power and unclear position of enterprise human resources development. The new pattern of human resources cultivation should be created to promote human resources development in different fields. Moreover, through the NCC construction, Chongqing's position as comprehensive transportation hub should be fully displayed to attract excellent human resources. At last, human resources around can be attracted by taking advantage of Western Development which further accelerates the formation of city circle, the incomplete market allocation can be changed to further achieve human resources allocation in China.

\subsection{WT Analysis of Chongqing Human Resources of Soft Power Development}

WT, which should be avoided in the practical operation, is the last thing Chongqing wants to face during the process of NCC construction and the worst combination during the process of human resources of soft power development. Once confronted, everything possible should be done to cut down the loss. WT is the worst condition which has to be adopted in the most difficult time; while WO and ST is the condition of mingled hope and fear which can be adopted in general; SO is the ideal condition which can be adopted at the best time. Therefore, during the development of human resources of soft power, one of the most important thing which relates to NCC construction of Chongqing is to study how to use the advantage and compensate the disadvantage, how to grasp opportunity and erase threats. 


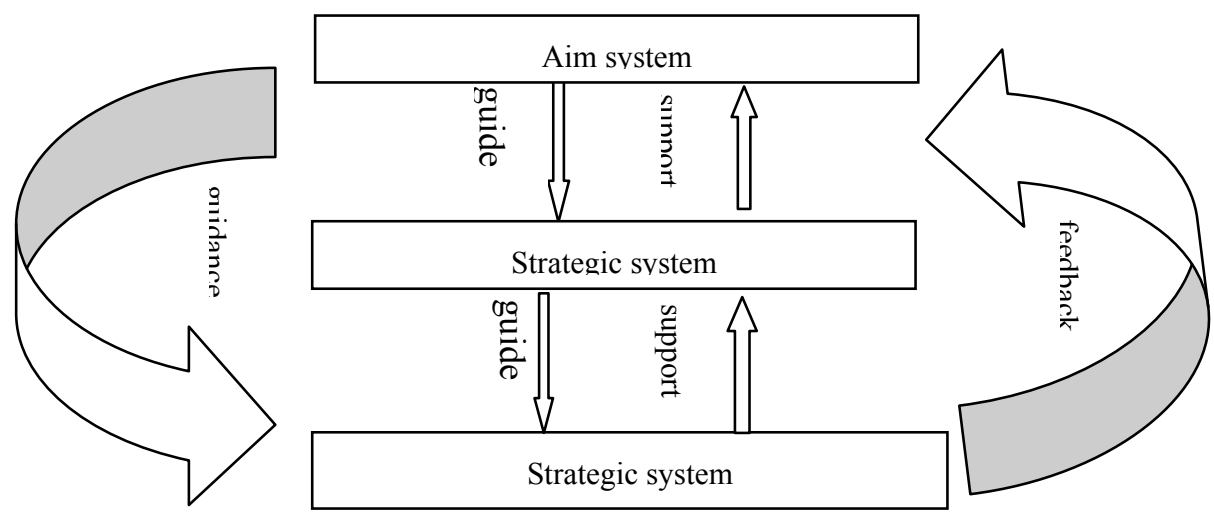

Figure 2. Implement strategies of Chongqing human resources of soft power development

In figure 2, strategies of Chongqing human resources of soft power development contains Aim system and Strategic system, they guide and support each other, and continuously improve through feedback.

\section{Implement Strategies of Chongqing Human Resources of Soft Power Development}

\subsection{The Overall Plan of Chongqing Human Resources of Soft Power Development}

\subsection{1 "Four-tion" and "One System" of Chongqing Human Resources of Soft Power Development}

During the process of human resources of soft power development, the idea of tactic system as base, strategic system as support and aim system as lead should be followed and human resources growing intensification, space internationalization, allocation marketization and requirement industrialization should be achieved to deliver numbers of excellent human resources to Chongqing's NCC construction, which can be seen in Figure 2.

\subsubsection{Five Strategies of Chongqing Human Resources of Soft Power Development}

The development of Chongqing human resources of soft power is not only an enlargement in quantity and scale, but a strategic developing process, providing key support for the achievement of aim system which includes five strategies-- human resources capital improvement, internationalization, security, highland construction and advancing human resources investment. Human resources capital improvement means to enlarge cultivation degree, increase the investment in science, research and development, strengthen construction of backbone teachers and research team, and enlarge graduates' education; internationalization means to promote optimization, competitive power, and change viewpoint to attract human resources domestic and abroad with favorable environment; highland construction means to form several human resources summit in national industry, accelerate hi-tech human resources' growth, steadily promote human resources in modern agriculture, increase investment in basic research, education, sanitation, and so on; investment will be beneficial for the continual, healthy and rapid development of human resources, increase aftereffect of human resources construction, and protect human resources resource through investment in education and research; security means to strengthen macro control, establish and perfect security system, highlight human resources protection related to national security, economic security, and national defense, key scientific and technical invention.

\section{2 "654" Strategic System of Chongqing Human Resources of Soft Power Development}

\subsubsection{Construction Strategy}

(1) Marketizaiton of human resources resource allocation: through the implement of "human resources market construction project", the market allocation needs to be established and completed. Price marketization can be achieved through perfecting human resources resource price system and modern human resources market network construction. On one hand, the market system is established according to scientific classification; on the other hand, intermediary organization to import human resources in the global area needs to be prepared to establish and integrate, open, orderly competitive market system needs to be formed at the same time.

(2) Macro control of human resources: on one hand, human resources development plan and macro control policy need to be made and implemented to supervise the operation and equal competition of human resources market; on the other hand, specific methods need to be made, especially strategic management for strategic human resources, to promote the fundamental change in human resources increasing, economic and social benefits of human resources. In addition, Chongqing's legal system of human resources needs to be strengthened. 
(3) Scientific management of human resources income and social security: on the one hand, insist the optimization of efficiency and give consideration to equity, distribute according to work and key elements, actively implement the participation of profit distribution according to producing key elements, like human capital and technology, implement "performance shares" in profit share for technical and managing creation human resources, perfect private income tax system, and tax-free policy can be applied for the income of various human resources which directly invests in social reproduction(namely, non consuming part); on the other hand, according to human resources characteristics, establish scientific social security system to make the vocational risk of human resources equal to market value.

(4) Personnel placement unit subjectivity: fully display the advantage in human resources allocation and employment. On one hand, operating system combined with stimulation and bind needs to be formed through scientific leadership and organization management system; on the other hand, modern human resource management system needs to be constructed to ensure the right of personnel placement, continually increasing human resources resource allocation and placement profits.

(5) Policy support for human resources: on one hand, support human resources level distribution, industry distribution and classification in policy, full display the special advantage of excellent ones, greatly promote the cultivation and import of human resources in new and high tech industry, backbone industry, key project, technical and managing creation; on the other hand, continually improve environment, support human resources construction, create favorable condition for new and hi-tech human resources to start their business in Chongqing, if possible, human resources business starting zone can be constructed.

(6) Human resources cultivation and imported managers' quality promotion: cultivate human resources and imported managers with four aspects, personal cultivation, human resources management and development, professional knowledge and skills of human resource management and development, related business and administration management.

\subsubsection{Import strategy}

(1) Widen human resources import channel: supervise human resources through the construction of human resources information database, including local people who are studying abroad intended to start business in Chongqing; at the same time, through close touch with human resources, actively introduce Chongqing' newest development and tendency, deliver the information that Chongqing is in need of human resources and actively import human resources through the medium of linkman.

(2) Import human resources through industry development and key project: strengthen the import of human resources team through enterprise as principal part, project as carrier, especially bidding for key project domestic and abroad; attract human resources to start their business in Chongqing through the support of optimized industry and nurturing project. In addition, multinational companies should be encouraged to develop in Chongqing to attract human resources skilled in management and technology.

(3) Import human resources through flexible flow of human resources: according to flexible flow of human resources--"come and go freely", strengthen the reform of HUMAN RESOURCES in management concept and system, complete contracting management, actively push forward system for appointment of posts and encourage human resources in other provinces to develop their technology and patent or start their business in Chongqing.

(4) Import human resources through platform: strengthen platform construction, providing development platform for human resources. First, science and research institute as platform, attract human resources domestic and abroad working in Chongqing. Second, market as platform, entrust international famous hunting companies as medium to get human resources required. Third, industry as platform, construct $\mathrm{PhD}$ science and research station in backbone, new and high-tech industries, strengthen the cooperation of universities and enterprises, and attract human resources as the tutor of $\mathrm{PhD}$ station.

(5) Enlarge communication and cooperation domestic and abroad and import human resources in the tendency of human resources flow: now the global economy confronts both challenges and opportunities, the condition of extra human resources in some countries can be grasped and human resources can be imported through active publication of human resources information in need worldwide. What's more, research meeting or symposium can be held in Chongqing through the sponsor of various organizations, research institutes and industry associations to enlarge the cooperation opportunity of human resources and projects in Chongqing. And human resources can be invited to give lectures, have sightseeing and visit relatives in Chongqing, which can be taken as an opportunity to recommend Chongqing to further achieve "intelligence import". 


\subsubsection{Cultivate Strategy}

(1) Display advantages to cultivate human resources: fully use the various beneficial policies authorized by the nation to guide the cooperation of universities, science and research institutes, new and high-tech enterprises and enterprise group to cultivate human resources, encourage young human resources to participate in technology development in enterprises and establish municipal scholarship to encourage $\mathrm{PhD}$ and graduates participating scientific research and productive practice.

(2) Strengthen the construction of human resources business starting team: allow scientific enterprises whose register capital are below $¥ 0.5$ million to register capital in several times, above $10 \%$ first time, to $50 \%$ in one year and to $100 \%$ in three years. Encourage people studying abroad to start business in Chongqing with their project or capital, and cooperate with universities, science and research institutes and enterprises project. Once granted, project support, interest discount on loan and financing guarantee will be offered to enterprise or institution and scientific and technical personnel, who bring their own scientific and technical achievements to start their business or implement achievement transformation in Chongqing, from central departments, committees or other provinces.

(3) Enlarge the educational cultivate degree of industry, study and research: first, speed the development of PhD science and research mobile and working stations, establish complete evaluation system and strengthen cultivate degree of human resources; second, cultivate human resources with research institutes and famous universities, improve the quality of graduates and achieve co-share of educational resources; third, strengthen the cultivation of human resources in national science fund committee, other scientific and technical plan and various research projects in Chongqing.

(4) Construct two-tier management system as cultivate carrier with "human resources cultivation project" as principle part: integrate Chongqing present human resources cultivating projects, confirm a leading key project with municipal committee and government attaching importance, municipal ministry of organization being in charge, while other human resources cultivating projects as the sub-projects, all the departments and regional governments should pay attention to the combination of the key project and local projects and make practical plan on the basis of the industry and regional features.

\section{Conclusion}

From the above analysis, it can be seen that during human resources soft power development, to achieve the strategic plan and measure, the ways below can be followed. First, human resources increasing intensives: enlarge human resources team with all means, fully display the potential of present human resources, optimize allocation and strengthen awards. Second, human resources space internationalization: on the basis of creating favorable conditions to attract human resources domestic to come to Chongqing, examine human resources work from the international point of view; actively participate international human resources competition and corporation to promote human resources internationalization. Third, human resources system marketization: adhere to the combination of market allocation and macro control, follow market economic rules and human resources resource development rules and fully display the function of market in human resources allocation. Four, human resources' requirement industrialization: further speed the construction of modern enterprise system, stimulate expectation and ability of human resources' requirement, make the enterprises absorb, employ, stimulate and train human resources according to the enterprises' development, and further promote the development.

\section{References}

Chongqing Annual Statistics. (2010). Chinese Statistics Press. Retrieved from http://www.cqtj.gov.cn/tjnj/2010/ yearbook/index.htm

Chongqing Annual Statistics. (2012). Chinese Statistics Press. Retrieved from http://www.cqtj.gov.cn/tjnj/2012/ indexch.htm

Chongqing Colleges and Universities Science and Technology Data. (2007). Edited by Chongqing Education Committee.

Chongqing Colleges and Universities Science and Technology Data. (2010). Edited by Chongqing Education Committee.

Chongqing Colleges and Universities Science and Technology Data. (2012). Chongqing Education Committee.

Human Resources Statistics. Human resources Flowing Department of Chongqing Human Resource and Social Security Bureau. Chongqing. (2008-2012) (in Chinese). Retrieved from http://www.cqhrss.gov.cn/u/cqhrss 
Luo, H. T. (2007). China's Western Human resources Resource Development Research. Beijing: China Press.

Luo, H. T., \& Wang, B. (2009). Strategic System Study on Chongqing High-level Human resources Import and Cultivation. Exploration, 2009(2).

Luo, H. T., Zhou, Q., He, L. L., \& Wang, B. (2005). Modern Human resources Resource Development. Chengdu: Sichuan People's Press.

Nye, J. (1990). Bound to Lead: The Changing Nature of American Power. New York Basic Books.

Nye, J. (2004). Soft Power: The Means to Success in World Politics. Public affairs, New York.

Report of China academicians of the Chinese Academy of Sciences and Engineering. (2008). Edited by China alumni association net. College magazine and $21^{\text {st }}$ century human resources newspaper. (in Chinese).

Science and Technology Data from National provinces and cities’ Education Ministry (Committee). (2006-2012) (in Chinese).

\section{Copyrights}

Copyright for this article is retained by the author(s), with first publication rights granted to the journal.

This is an open-access article distributed under the terms and conditions of the Creative Commons Attribution license (http://creativecommons.org/licenses/by/3.0/). 